\title{
Role of protein kinase $C \beta$ in rhythmic contractions of human pregnant myometrium
}

\author{
Katsuhiko Yasuda, Tsuyoshi Nakamoto, Masahiro Yasuhara, Hidetaka Okada, Tatsuya Nakajima, \\ Hideharu Kanzaki, Masatoshi Hori ${ }^{1}$ and Hiroshi Ozaki ${ }^{1}$ \\ Department of Obstetrics and Gynecology, Kansai Medical University, 10-15 Fumizono-cho, Moriguchi, Osaka \\ 570-8507, Japan and ${ }^{1}$ Department of Veterinary Pharmacology, Graduate School of Agriculture and Life Sciences, \\ The University of Tokyo, Bunkyo-ku, Yayoi 1-1-1, Tokyo 113-8657, Japan
}

Correspondence should be addressed to K Yasuda; Email: yasuda@takii.kmu.ac.jp

\begin{abstract}
To assess the role of protein kinase $\mathrm{C} \beta$ (PKC $\beta$ ) in human myometrial contractions during pregnancy, we evaluated the effect of a PKC $\beta$ inhibitor (LY333531) on the pregnant and nonpregnant myometrial contractions and compared the level of PKC $\beta$ in the pregnant myometrium with that in the nonpregnant myometrium. The effects of LY333531 on the myometrial contractions were examined by measuring contractile activity (frequency and amplitude). PKC $\beta$ in human myometrium was assessed at mRNA level using real-time PCR method. The characteristics of contractile activity were different between the pregnant and the nonpregnant myometrium. The amplitude of rhythmic contractions in the preterm and term myometrium was increased 2- to 2.5-fold when compared with that in the nonpregnant myometrium, but the frequency of rhythmic contractions was decreased by about half. LY333531 $\left(10^{-6} \mathrm{M}\right)$ reduced the increased amplitude in the preterm and term myometrium by about $50 \%$, and the inhibitory effects of LY333531 in the pregnant myometrium were significantly greater than that in the nonpregnant myometrium (about 50 vs $25 \%$ ). However, the frequency in the pregnant and nonpregnant myometrium was not influenced by LY333531. Real-time PCR revealed a significant, five- to sevenfold increase in the expression of PKC $\beta$ mRNA in the preterm and term myometrium when compared with the nonpregnant myometrium. These findings suggest that the increased amplitude of human myometrial contractions during pregnancy is related to the increased level of PKC $\beta$. А РКС $\beta$ inhibitor may reduce preterm uterine contractions and prevent preterm delivery.

Reproduction (2007) 133 797-806
\end{abstract}

\section{Introduction}

Clinical and experimental evidence has indicated that the primary pathogenic mechanisms involved in preterm delivery are 1) activation of the hypothalamus-pituitaryadrenal axes of the mother and the fetus; 2 ) inflammation of the amnion, chorion, and deciduas; 3) decidual hemorrhage; and 4) pathologic distension of the uterine myometrium. However, these mechanisms share a common final pathway that results in uterine smooth muscle contractions. It is well known that oxytocin and prostaglandin $F_{2} \alpha\left(P G F_{2} \alpha\right)$ induce pregnant uterine contractions (Akerlund et al. 1987, Keirse 1992, Moutquin et al. 2000). Therefore, these agents have been used clinically for induction of delivery or termination of pregnancy. Agonists such as oxytocin, PG $F_{2} \alpha$, endothelin-1, and acetylcholine increase intracellular $\mathrm{Ca}^{2+}$ concentrations $\left(\left[\mathrm{Ca}^{2+}\right] \mathrm{i}\right)$ and induce myometrial contractions (Anwer \& Sanborn 1989,
Sakata et al. 1989, Sakata \& Karaki 1992, Wray 1993, Szal et al. 1994, Kim et al. 1995). After the agonists bind to their respective receptors, phosphoinositide (PI) turnover occurs in uterine smooth muscle cells (Marc et al. 1986, Schrey et al. 1988, Schiemann et al. 1991) and two important signal transduction molecules, inositol 1,4,5-trisphosphate and diacylglycerol, are produced. Inositol 1,4,5-trisphosphate releases $\mathrm{Ca}^{2+}$ from intracellular $\mathrm{Ca}^{2+}$ stores and activates calmodulin. The activated calmodulin $\left(\mathrm{Ca}^{2+}\right.$-calmodulin complex) induces phosphorylation of myosin light chain (MLC) via MLC kinase (MLCK) and causes smooth muscle contractions (Somlyo \& Somlyo 1994). On the other hand, it is well known that MLC phosphatase (MLCP) relaxes smooth muscle contractions by dephosphorylating phosphorylated MLC (Somlyo \& Somlyo 1994, Savineau \& Marthan 1997). Recently, the importance of regulation of smooth muscle contractions independent of changes in $\mathrm{Ca}^{2+}$ levels, referred to as $\mathrm{Ca}^{2+}$ sensitization, was 
highlighted (Karaki et al. 1997, Hori \& Karaki 1998, Somlyo \& Somlyo 2003). $\mathrm{Ca}^{2+}$ sensitization is mediated via an inhibition of MLCP, and abolishes the dephosphorylation of MLC and induces an increase of contractility. In vascular smooth muscle cells, $\mathrm{Ca}^{2+}$ sensitization of contractile elements is induced by a pathway that is mediated by the protein kinase $\mathrm{C}$ (PKC)potentiated inhibitor protein of $17 \mathrm{kDa}$, called $\mathrm{CPI}-17$, an endogenous inhibitory protein of MLCP (Eto et al. 1997, 2001). CPI-17 can be phosphorylated by PKC, and thereby, inhibit the catalytic subunit of MLCP ( $\mathrm{Li}$ et al. 1998, Hamaguchi et al. 2000, Kitazawa et al. 2000, Eto et al. 2004) and induce an increase of smooth muscle contractility. Recently, we found that PKC, especially PKC $\beta$, modulated CPI-17 in human myometrium and increased $\mathrm{Ca}^{2+}$ sensitization of the contractile elements during pregnancy (Ozaki et al. 2003).

Diacylglycerol, another phosphoinositide product in PI turnover, stimulates PKC, which phosphorylates various cellular functional proteins (Nishizuka 1995, Webb et al. 2000). It has been reported that PKC activation by phorbol ester inhibits gastric smooth muscle contractions by inhibiting inositol phosphate production (Ozaki et al. 1992), but induces vascular and tracheal smooth muscle contractions by increasing the $\mathrm{Ca}^{2+}$ sensitivity of contractile elements (Morgan \& Morgan 1984, Sato et al. 1988, Ozaki et al. 1990, Sato et al. 1992). In rat myometrial cells, the PKC activation inhibits $\mathrm{Ca}^{2+}$ channel activity (Kusaka \& Sperelakis 1995), and thus PKC activation in the rat myometrium has an inhibitory effect on contractions (Baraban et al. 1985, Savineau \& Mironneau 1990, Phillippe 1994, Kim et al. 1996). In contrast, in cultured cells of rat portal veins, PKC activation increases $\mathrm{Ca}^{2+}$ channel activity (Loirand et al. 1990). Additionally, in human myometrium, PKC activation has been shown to play an important role in the agonist-induced smooth muscle contractions (Morrison et al. 1996, Breuiller-Fouche et al. 1998). These results suggest that the effects of PKC activation are tissue dependent and species dependent, and consist of both contractile and relaxation responses. Different mechanisms appear to contribute to the different effects of PKC activation in tissues and species. Recently, we found that the expression of PKC $\beta$ and the contractile force in the pregnant myometrium were significantly increased at the late stage of pregnancy (37-40 weeks of gestation) when compared with those in the nonpregnant myometrium (Ozaki et al. 2003). Additionally, we found that the inhibitory effect of PKC $\beta$ inhibitor on high potassium-induced smooth muscle contractions was significantly greater in the pregnant myometrium than in the nonpregnant myometrium (Ozaki et al. 2003). These results suggest that inhibitors of PKC $\beta$ have a potent ability to inhibit not only term uterine contractions but also preterm uterine contractions and prevent preterm delivery. In this study, we compared the expression of PKC $\beta$ in the human preterm myometrium with those in the nonpregnant and term myometrium, and also compared the inhibitory effects of PKC $\beta$ inhibitors on the preterm uterine contractions in vitro with those on the nonpregnant and term uterine contractions.

\section{Materials and Methods}

\section{Chemicals}

Atonin-0 (oxytocin) was purchased from Teizo (Tokyo, Japan). LY333531, PKC $\beta$ inhibitor, was donated by Kissei Pharmaceutical Co. (Matsumoto, Nagoya, Japan). Go6976 (inhibitor of $\mathrm{PKC} \alpha$ and $\mathrm{PKC} \beta$ ), rottlerin (inhibitor of $\mathrm{PK} \delta$ and PKC ), and Ro-31-8220 (nonspecific inhibitor of PKC) were purchased from Calbiochem-Novabiochem Co. (San Diego, CA, USA), and TRIzol reagent and DNase I Amplification Grade were purchased from Invitrogen. ReverTra Ace- $\alpha$ kit including reverse transcriptase, RT buffer, and the deoxy-ATP, -CTP, -GTP, and -TTP mixtures (dNTPs) were purchased from Toyobo (Osaka, Japan). SYBR green I dye for the molecular biology experiments was purchased from FMC Bioproducts (Rockland, ME, USA). Taq DNA polymerase, PCR buffer, and RNase inhibitor were supplied by Wako (Tokyo, Japan). Glycogen for the molecular biology experiments was purchased from Roche Diagnostics Corporation.

\section{Selection of patients and tissue collection}

Tissue samples were obtained from patients undergoing hysterectomy or cesarean section. This study was approved by the ethics committee of our university and performed according to the Declaration of Helsinki. Written informed consent was obtained from each patient. The term delivery group consisted of pregnant women (30-42 years of age) who underwent elective lower segment cesarean section for previous cesarean section, cephalopelvic disproportion, or breech presentation at 37-39 weeks of gestation. The preterm delivery group consisted of pregnant women (23-37 years of age) who underwent cesarean section for preeclampsia, non-reassuring fetal heart rate, premature rupture of membrane, or intrauterine growth retardation at 26-36 weeks of gestation. Routine cesarean section was carried out under epidural or spinal anesthesia. After delivery of the infant and placenta, a sample of the myometrium (length, 2-3 cm; width, 3-6 mm; thickness, 4-7 mm) was taken from the upper margin of the lower uterine segment incision using tissue forceps and scissors before the administration of oxytocin.

The nonpregnant group consisted of ten nonpregnant women (35-49 years of age) with a menstrual cycle, who underwent total abdominal hysterectomy for benign ovarian tumor, malignant ovarian tumor (stage 1), cervical cancer (carcinoma in situ or stage 1a), or endometrial cancer (stage $1 \mathrm{a}$ or $1 \mathrm{~b}$ ). Nine women 
underwent operations at secretary phase during their menstrual cycles and one woman underwent at proliferative phase. Myometrial samples were taken at the junction of the inner cervical os and uterine corpus.

All obtained tissue samples were immediately submerged in ice-cold University of Wisconsin Solution (Belzer UW, Dupont Pharma, Wilmington, The Netherlands) and transported to the laboratory. We prepared myometrial strips from both the nonpregnant and the pregnant myometrial tissue samples, and evaluated the contractile activity and the effects of the PKC $\beta$ inhibitor, LY333531, on both spontaneous and oxytocin-induced myometrial contractions. In the same tissue samples, the expression of PKC $\beta$ mRNA was evaluated using real-time PCR.

\section{RNA isolation and RT}

Total RNA was extracted from the myometrium by the acid guanidinium isothiocyanate-phenol-chloroform method (Chomczynski \& Sacchi 1987) using TRIzol reagent, and the concentration of RNA was adjusted to $1 \mu \mathrm{g} / \mu \mathrm{l}$ with RNase-free distilled water. RT was performed using ReverTra Ace- $\alpha$-kit according to manufacturer's instructions. One microgram of total RNA was treated with ReverTra Ace reverse transcriptase in $20 \mu \mathrm{l}$ reaction buffer. Reaction was performed at $30^{\circ} \mathrm{C}$ for $10 \mathrm{~min}$, at $42{ }^{\circ} \mathrm{C}$ for $20 \mathrm{~min}$ and stopped at $99^{\circ} \mathrm{C}$ for 5 min using Takara PCR Thermal Cycler MP (Takara Shuzo, Kyoto, Japan). Finally, the total volume of the solution including the first-strand cDNA was adjusted to $100 \mu \mathrm{l}$ by adding distilled water and stored at $-20{ }^{\circ} \mathrm{C}$ until real-time PCR analysis. For a negative control, the same reaction was performed without reverse transcriptase.

\section{Real-time PCR analysis for PKC $\beta$}

In the present experiment, we used the hot start method using recombinant Taq DNA polymerase Gene Taq supplied by Nippon Gene (Toyama, Japan). As an internal control, the elongation factor (EF)- $1 \alpha$ gene, which is valid as a reference 'housekeeping' gene for transcription profiling, is used (Frost \& Nilsen 2003). The oligonucleotide primers were synthesized by Proligo Japan (Kyoto, Japan). The forward (F) and reverse (R) oligonucleotide primers for $\mathrm{PKC} \beta$ and $\mathrm{EF}-1 \alpha$ were as follows: PKC $\beta$ (F: AAATTGCCATCGGTCTGTTC; R: GCCATGTAGTCTGGAGTGCC; 181-base: 1346-1526) and EF-1 $\alpha$ (F: TCTGGTTGGAATGGTGACAACATGC; R: AGAGCTTCACTCAAAGCTTCATGG; 329-base: 595-923). The PCR was performed in a total volume of $25 \mu$ l containing $2 \mu$ l of the above-described solution of cDNA, $1 \mu \mathrm{l}$ each of the $3^{\prime}$ and $5^{\prime}$ primers $(3.75 \mathrm{pmol}$ each), $1 \mu \mathrm{l} \mathrm{MgCl}_{2}$ (25 mM), $2 \mu \mathrm{l}$ dNTP $(2.5 \mathrm{mM}), 2.5 \mu \mathrm{l}$ $10 \times$ Gene Taq Universal Buffer, $0.375 \mathrm{U}$ recombinant Taq DNA polymerase Gene Taq, $0.075 \mu \mathrm{l}$ MAB for Hot
Start PCR anti-Taq high, and 1/75000 SYBR green I nucleic acid gel stain. After PCR, a melting curve was constructed by increasing the temperature from 65 to $95^{\circ} \mathrm{C}$ at a temperature transition rate of $0.5^{\circ} \mathrm{C} / 30 \mathrm{~s}$. After melting curve analysis, the concentration of each sample was calculated from the threshold cycle (Ct). To facilitate a comparison of mRNA expression, the $\mathrm{Ct}$ values of PKC $\beta$ from each sample were normalized by $\mathrm{EF}-1 \alpha \mathrm{Ct}$ values obtained from that same sample. The $\mathrm{Ct}$ values were averaged from triplicate values. The differences between the mean $\mathrm{Ct}$ values of PKC $\beta$ and those of EF- $1 \alpha$ were calculated as follows: $\Delta \mathrm{Ct}(\mathrm{PKC} \beta)=$ $\mathrm{Ct}(\mathrm{PKC} \beta)-\mathrm{Ct}(\mathrm{EF}-1 \alpha)$. The final result was expressed as $2^{-\Delta \mathrm{Ct}(\mathrm{PKC} \beta)}$.

\section{Measurement of smooth muscle contractions and evaluation of contractile activity}

After the tissue samples were obtained from nonpregnant and pregnant women, the tissue samples were cut into longitudinal strips $\sim 20 \mathrm{~mm}$ long and $1 \mathrm{~mm}$ wide. Each strip was attached to a holder under $1 \mathrm{gf}(9.807 \mathrm{mN})$ resting tension. After equilibration for $60 \mathrm{~min}$ in a physiological saline solution (PSS), each strip was repeatedly exposed to $72.7 \mathrm{mM} \mathrm{KCl}$ solution (high $\mathrm{K}^{+}$ solution) until the response became stable. PSS contained the following (in $\mathrm{mM}$ ): $\mathrm{NaCl} 136.9 ; \mathrm{KCl} 5.4$; $\mathrm{CaCl}_{2}$ 1.5; $\mathrm{MgCl}_{2}$ 1.0; $\mathrm{NaHCO}_{3}$ 23.8; glucose 5.5; and EDTA 0.01 . The high $\mathrm{K}^{+}$solution was prepared by replacing $\mathrm{NaCl}$ with an equimolar amount of $\mathrm{KCl}$. These solutions were saturated with a $95 \% \mathrm{O}_{2} / 5 \% \mathrm{CO}_{2}$ mixture at $37^{\circ} \mathrm{C}(\mathrm{pH}$ 7.4). We employed the contraction induced by high $\mathrm{K}^{+}$solution as a reference response. After exchanging high $\mathrm{K}^{+}$solution with PSS, oxytocin was added to the solution to induce rhythmic contractions and the contractions were observed for more than 30 min until they were stable. In this study, we selected myometrial strips that responded to $50 \mu \mathrm{U} / \mathrm{ml}$ oxytocin (final concentration) and evaluated their frequency and amplitude. Oxytocin was not added to the nonpregnant myometrial strips and some of the pregnant myometrial strips showed spontaneous contractions. Spontaneous and oxytocin-induced contractions were recorded isometrically with a force-displacement transducer (Model TB611T: Nihon Kohden, Tokyo, Japan) that was connected to a Model 3134 strain amplifier and Model 3056 ink-writing recorder (Yokogawa, Tokyo, Japan), and the data were simultaneously inputted into a personal computer (OS, Microsoft Windows 2000 Professional). The data inputted into the computer were analyzed with the Unique Acquisition software package (Unique Medical Co., Ltd, Tokyo, Japan).

To evaluate the contractile activity, myometrial strips that had more than six peaks of spontaneous or oxytocin-induced contractions were analyzed. The amplitude of each contraction was calculated from the base line and the top of the peak and was presented 
as the mean value of more than six peaks. The frequency of each contraction was calculated from intervals of the corresponding peaks and was presented as the number of cycles per $1 \mathrm{~h}$. The evaluation of the inhibitory effect of LY333531 on the contractile activity was performed using the same method as described above after adding the inhibitor to the solution. In the present study, the effects of LY333531 were evaluated $1 \mathrm{~h}$ after the administration of the inhibitor, because the effects of LY333531 were stable at $1-2 \mathrm{~h}$ after the administration.

\section{Statistical analysis}

The results were expressed as the mean \pm s.E.M. Statistical analysis was performed using the unpaired Student's $t$-test for comparisons between pairs of groups and oneor two-way ANOVA followed by Dunnett's test or Tukey's test for comparisons among more than three groups. Values of $P<0.05$ were considered to indicate statistical significance.

\section{Results}

\section{Effects of various PKC inhibitors on the rhythmic contractions of myometrial strips}

We induced the rhythmic contractions using oxytocin to examine the effects of various PKC inhibitors on the myometrial contractions. As shown in Fig. 1, the concentration of $10^{-6} \mathrm{M}$ of LY333531 and Go6976, inhibitors of PKC $\beta$, remarkably inhibited the amplitude of the oxytocin-induced contractions of the term myometrial strip. Each amplitude of the contractions was decreased by about $50 \%$ respectively. However, the concentration of $10^{-6} \mathrm{M}$ of rottlerin, an inhibitor of PK $\delta$ and $\operatorname{PKC} \theta$, had no influence on the oxytocin-induced contractions. The concentration of $10^{-6} \mathrm{M}$ of Ro-318220, a nonspecific inhibitor of PKC, slightly inhibited the amplitude of the oxytocin-induced contractions. The inhibitory effect of Ro-31-8220 on the oxytocin-induced contractions was extremely less than that of both LY333531 and Go6976, while none of the PKC inhibitors have influence on the frequency of the oxytocin-induced contractions.

\section{Effect of a PKC $\beta$ inhibitor, LY333531, on the rhythmic contractions of myometrial strips}

In the present study, spontaneous and rhythmic contractions were found in all nonpregnant myometrial strips and in some of the preterm myometrial strips, while no spontaneous contractions were found in the other preterm myometrial strips. However, oxytocin induced rhythmic contractions in the preterm and term myometrial strips and mimicked the spontaneous contractions that were found in some of the preterm myometrial strips. Figure 2 shows a typical example of the inhibitory effect of LY333531 on pregnant myometrial contractions. The amplitude of spontaneous contractions was decreased dose dependently. The concentration of $10^{-6} \mathrm{M}$ of LY333531 decreased the amplitude by about $50 \%$. Therefore, we employed $10^{-6}$ M LY333531 to compare its effect on myometrial contractions in the four groups (the nonpregnant group with spontaneous contractions, the preterm group with

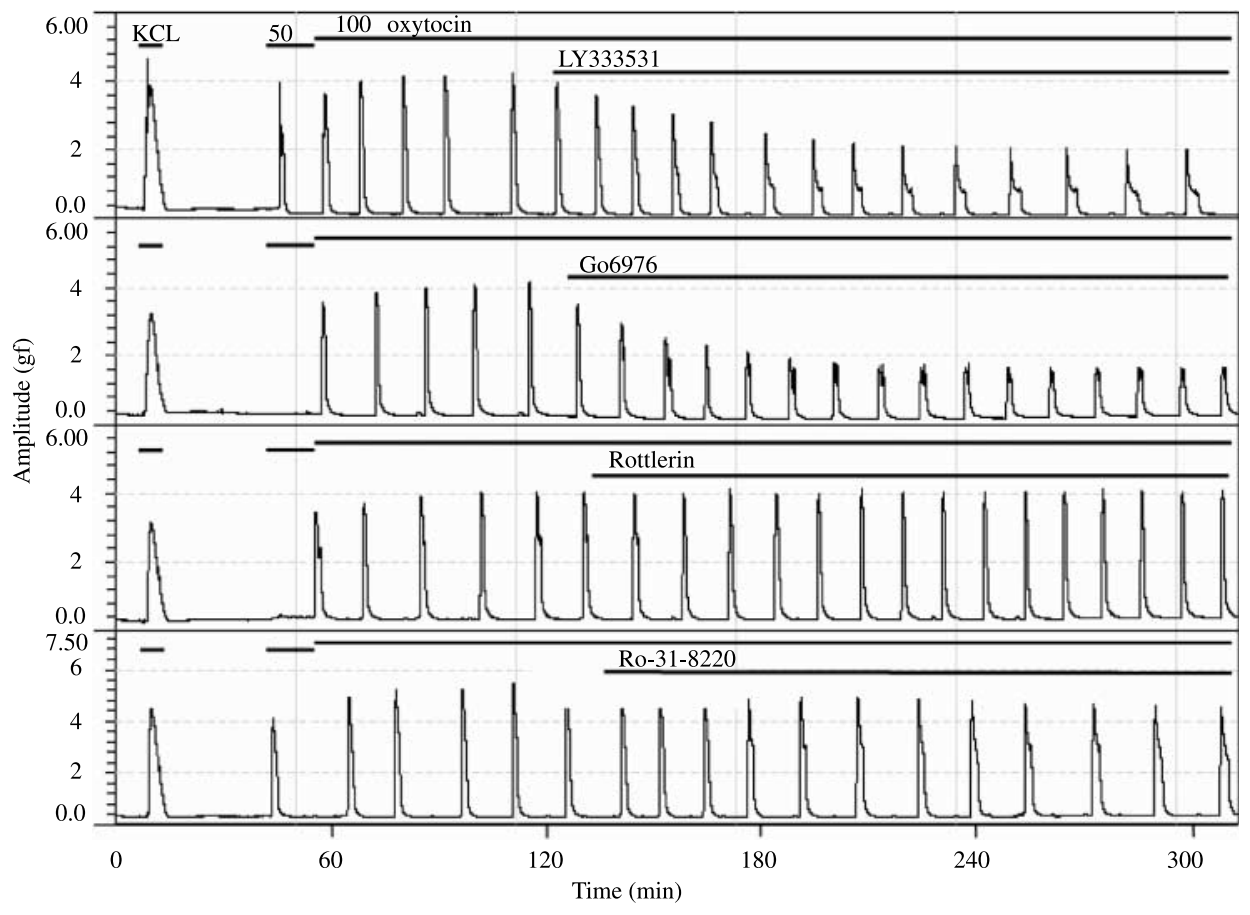

Figure 1 Effects of various PKC inhibitors on smooth muscle contractions in the human myometrium. Rhythmic contractions were induced by oxytocin (final concentration, $100 \mu \mathrm{U} / \mathrm{ml}$ ) in four myometrial strips from a term woman who underwent cesarean section for previous cesarean section at 38 weeks of gestation. Two strips responded to $50 \mu \mathrm{U} / \mathrm{ml}$ oxytocin and another two strips responded to $100 \mu \mathrm{U} / \mathrm{ml}$ oxytocin. Amplitude (force) is expressed in gram force and time is expressed in minutes. Various PKC inhibitors $\left(10^{-6} \mathrm{M}\right)$ were added into PSS after respective oxytocin-induced contractions were stable. 


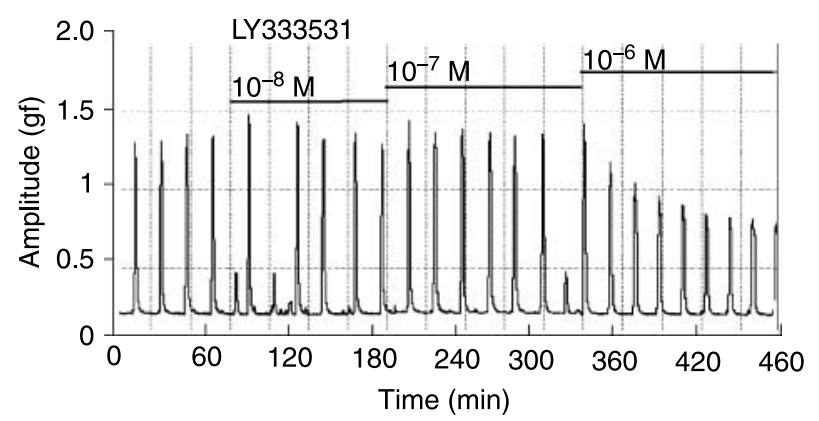

Figure 2 Dose-dependent effect of a PKC $\beta$ inhibitor, LY333531, on smooth muscle contractions in the human myometrium. A representative trace of spontaneous contractions in a preterm myometrial strip from a woman in her 36th week of pregnancy and the inhibitory effect of cumulatively increasing concentrations of LY333531 $\left(10^{-6}-10^{-8} \mathrm{M}\right)$.

spontaneous contractions, the preterm group with oxytocin-induced contractions, and the term group with oxytocin-induced contractions). As shown in Fig. 3Aa, LY333531 slightly inhibited the spontaneous contractions in the nonpregnant myometrium. On the other hand, LY333531 remarkably inhibited the spontaneous and oxytocin-induced contractions in the preterm myometrial strips (Fig. $3 \mathrm{~A} b$ and $\mathrm{A} c$ ), and these inhibitory effects became stable $1-2 \mathrm{~h}$ after the administration of LY333531. Additionally, a similar inhibitory effect was observed in oxytocin-induced contractions in the term myometrial strips (Fig. 3Ad). On the other hand, spontaneous and oxytocin-induced contractions in control myometrial strips were continued rhythmically without a reduction during the period of assessment of the inhibitory effect of LY333531 (Fig. 3Ba-d). The results of the inhibitory effects of LY333531 on the contractile activity in each group are summarized in Table 1.

We evaluated the inhibitory effect of LY333531 on the myometrial contractions in each group as a relative ratio (with the original value treated as $100 \%$ ), because there was wide variation in both the amplitude and the frequency among individual strips in the same group and also wide variation in the amplitude and the frequency between the strips of different groups, especially between the nonpregnant and the pregnant groups (Table 1). As shown in Fig. 4A, the relative ratio in the frequency was similar between the original and the post-treatment level in all groups after the administration of LY333531. In contrast to the frequency, a significant inhibitory effect of LY333531 on the amplitude of myometrial contractions was found in all groups (Fig. 4B). The relative ratio in the amplitude was significantly decreased to $75 \pm 2.4 \%$ in the nonpregnant group $(P<0.01$ versus the original value), $55 \pm 5.9 \%$ in the preterm group with spontaneous contractions $(P<0.01), 52 \pm 3.5 \%$ in the preterm group with oxytocin-induced contractions $(P<0.01)$, and $49 \pm$ $4.5 \%$ in the term group with oxytocin-induced contractions $(P<0.01)$. Additionally, the inhibitory effect of
LY333531 on myometrial contractions in the three pregnant groups was significantly greater than that in the nonpregnant group $(P<0.01)$. However, the effect did not differ among the three pregnant groups.

\section{Expression of PKC $\beta$ mRNA}

Real-time PCR revealed that the level of PKC $\beta$ mRNA expression in both the preterm and the term myometrium was significantly increased when compared with that in the nonpregnant myometrium (Fig. 5). The relative expression of PKC $\beta$ mRNA (ratio to EF- $1 \alpha$ mRNA) in the preterm myometrium that showed spontaneous contractions was significantly greater than that in the nonpregnant myometrium $\left(6.55 \pm 1.11 \times 10^{-3}\right.$ vs $\left.0.95 \pm 0.20 \times 10^{-3}, P<0.01\right)$. The relative expression of PKC $\beta$ mRNA in the preterm and term myometrium that showed only oxytocin-induced contractions was $4.92 \pm 0.59 \times 10^{-3}$ and $5.97 \pm 1.38 \times 10^{-3}$ respectively and each expression was also significantly greater than that in the nonpregnant myometrium $(P<0.01$ respectively). However, no significant difference in the relative expression of PKC $\beta$ mRNA was found between the preterm and the term myometrium.

\section{Discussion}

Figure 1 revealed the effects of various PKC inhibitors on the pregnant myometrial contractions. Of used PKC inhibitors, the inhibitors of PKC $\beta$, LY333531, and Go6976, were most effective, and the concentration of $10^{-6} \mathrm{M}$ of each inhibitor of PKC $\beta$ decreased the amplitude of the oxytocin-induced contractions in the term myometrium by about $50 \%$ respectively. However, the inhibitor of $\mathrm{PKC} \delta$ and $\mathrm{PKC} \theta$, rottlerin, had no influence on the contractions at the same concentration, and the nonspecific inhibitor of PKC, Ro-31-8220, had few inhibitory effects on the contractions. These results suggest that inhibitor of $\mathrm{PKC} \beta$ is a candidate for prevention of premature uterine contractions. Of the two inhibitors of PKC $\beta$, Ly333531 is more selective to PKC $\beta$ than Go6976. It was reported that Go6976 was a powerful inhibitor against both $\mathrm{PKC} \alpha$ and $\mathrm{PKC} \beta$ (Martiny-Baron et al. 1993). The authors reported that the inhibition $\left(\mathrm{IC}_{50}\right)$ of PKC $\alpha$ and PKC $\beta$ was 2.3 and $6.2 \mathrm{nM}$ respectively, when PKC activity assay was performed in vitro using recombinant PKC isozymes and PKC from rat brain. It was reported that the $\mathrm{IC}_{50}$ of PKC $\alpha$ and PKC $\beta$ in LY333531 was 360 and 4.7-5.9 nM respectively (Jirousek et al. 1996). Therefore, we employed LY333531, more selective inhibitor of PKC $\beta$, to examine the inhibitory effect of inhibitors on the myometrial contractions.

In the present study, in which we set the resting force as $1 \mathrm{gf}$, the amplitude of spontaneous contractions in the preterm myometrium was 2.5 -fold greater than that in 
A

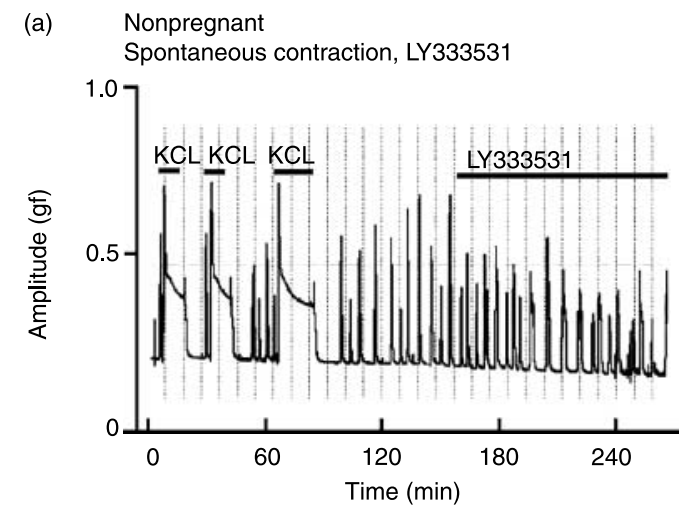

(c) Preterm-oxy

Oxytocin-induced contraction, LY333531

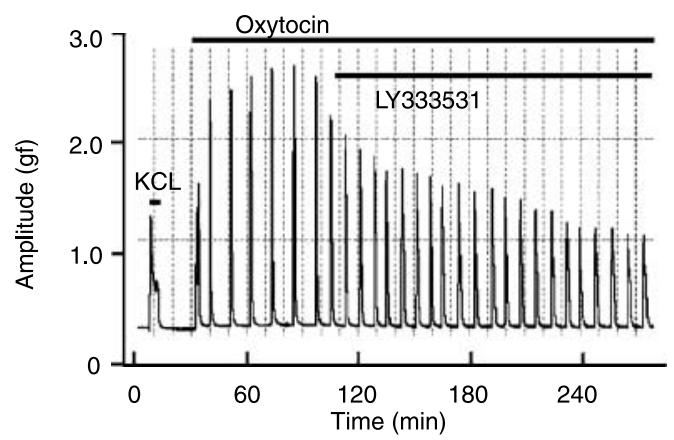

B
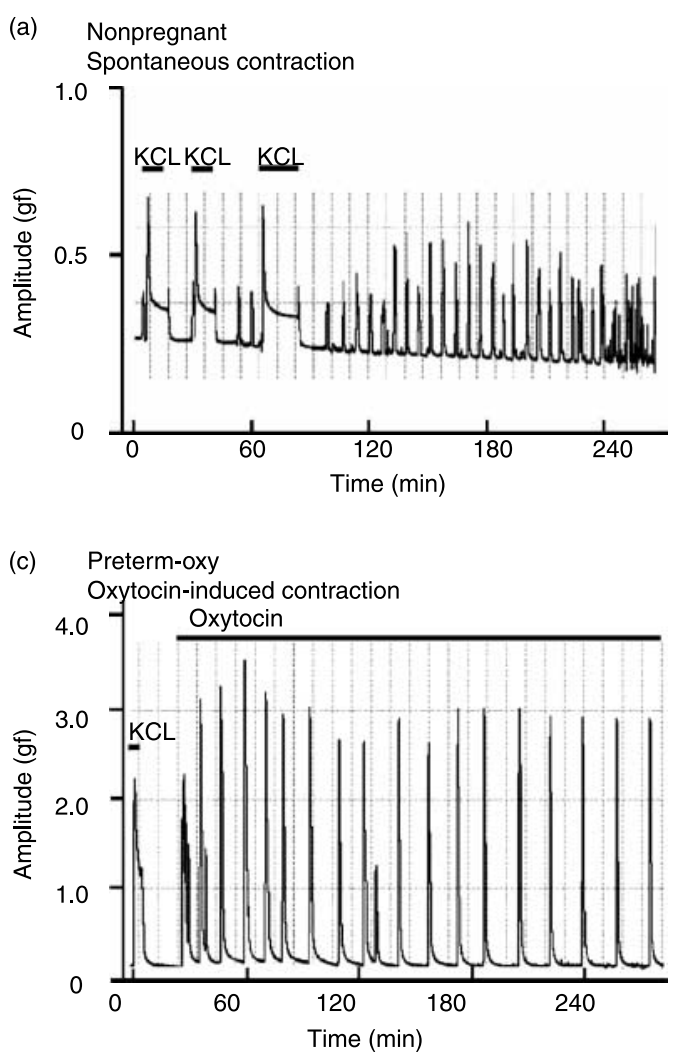

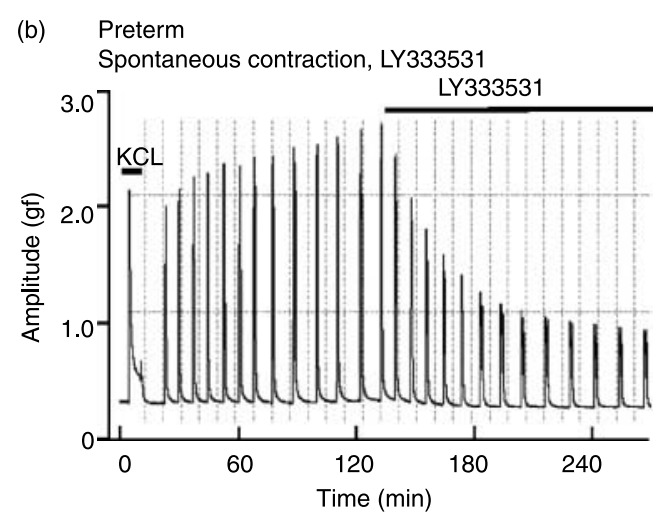

(d) Term-oxy
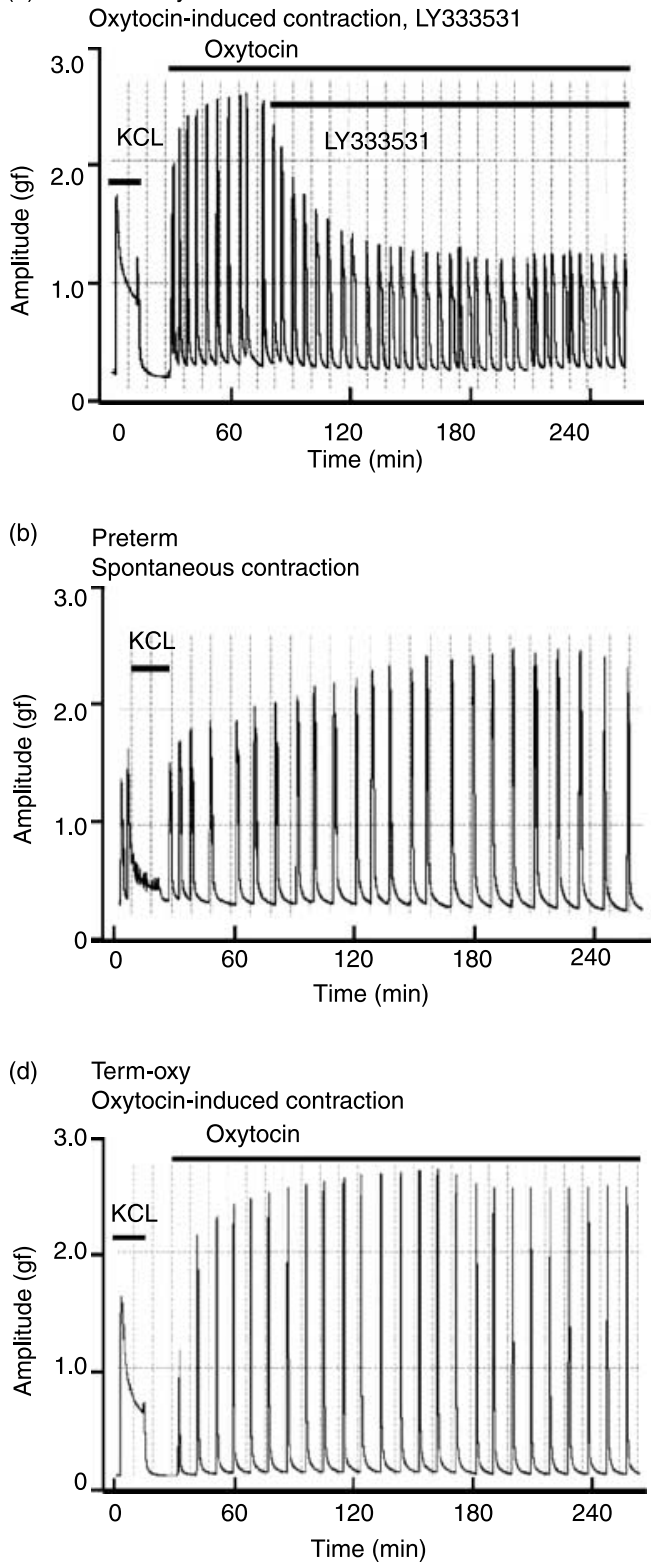
Table 1 Effect of a PKC $\beta$ inhibitor (LY333531: $10^{-6}$ M) on contractile activity.

\begin{tabular}{|c|c|c|c|c|c|}
\hline \multirow[b]{2}{*}{ Group } & \multirow[b]{2}{*}{$N$} & \multicolumn{2}{|c|}{ Frequency (cycle/h) } & \multicolumn{2}{|c|}{ Amplitude (gf) } \\
\hline & & LY333531 (-) & LY333531 (+) & LY333531 (-) & LY333531 (+) \\
\hline Nonpregnant & 10 & $13.41 \pm 1.87$ & $14.77 \pm 2.65$ & $0.69 \pm 0.11$ & $0.52 \pm 0.09$ \\
\hline Preterm & 5 & $5.70 \pm 0.88^{*}$ & $5.56 \pm 0.84^{\dagger}$ & $1.86 \pm 0.26^{\dagger}$ & $1.02 \pm 0.18^{* \neq}$ \\
\hline Preterm-oxy & 10 & $5.24 \pm 0.60^{+}$ & $6.54 \pm 0.99^{\dagger}$ & $1.50 \pm 0.25^{\dagger}$ & $0.80 \pm 0.15^{\ddagger}$ \\
\hline Term-oxy & 10 & $5.37 \pm 0.74^{+}$ & $5.65 \pm 0.67^{+}$ & $1.58 \pm 0.21^{\dagger}$ & $0.81 \pm 0.13^{\S}$ \\
\hline
\end{tabular}

The effect of LY333531 was evaluated by measuring the frequency and the amplitude of spontaneous or oxytocin-induced contractions in the nonpregnant, preterm, and term myometrium after the administration of LY333531 $\left(10^{-6} \mathrm{M}\right)$. Values are expressed as the mean \pm S.E.M. ${ }^{*} P<0.05$ versus nonpregnant, ${ }^{+} P<0.01$ versus nonpregnant. ${ }^{\ddagger} P<0.05$ vs LY333531 (-), ${ }^{\S} P<0.01$ vs LY333531 (-).

the nonpregnant myometrium (Table 1). Similarly, the amplitude of oxytocin-induced contractions in the preterm and term myometrium was twofold greater than the amplitude of spontaneous contractions in the nonpregnant myometrium. In contrast to the amplitude, the frequency of contractions in the preterm and term myometrium was significantly lower than that in the nonpregnant myometrium. The frequency in the preterm and term myometrium was $<50 \%$ of the frequency in the nonpregnant myometrium.

These facts suggest that, when we evaluate the inhibitory effect of inhibitors on the myometrial contractions, the characteristics of the contractions in the nonpregnant and pregnant myometrium must be considered. Therefore, we evaluated the inhibitory effect of LY333531 on the contractions as the effect on amplitude and frequency. We presented the effect of LY333531 on the amplitude and the frequency of the contractions as a relative ratio (with the original value treated as $100 \%$ ).

LY333531, which has been shown to inhibit MLCP activity in the rat and the human myometria by phosphorylating MLCP (Ozaki et al. 2003), inhibited the smooth muscle contractions in the nonpregnant and pregnant myometrium, but not the frequency in the same myometria. However, the inhibitory effects of LY333531 on smooth muscle contractions were different between the nonpregnant and the pregnant myometrium. In the nonpregnant myometrium, LY333531 decreased the amplitude of spontaneous contractions by about $25 \%$ at the concentration of $10^{-6} \mathrm{M}$ (Fig. 4). However, in the preterm myometrium with spontaneous contractions, the effect of LY333531 on the amplitude was about twofold greater than that in the nonpregnant myometrium (45 vs $25 \%, P<0.01)$. A similar phenomenon was found in oxytocin-induced contractions in the preterm and term myometrium respectively. LY333531 decreased the amplitude of the oxytocin-induced contractions in the preterm and term myometrium by 48 and $51 \%$ respectively, and each effect was significantly greater than that in the nonpregnant myometrium $(P<0.01$ respectively). In the present study, it was also revealed that $10^{-6} \mathrm{M}$ LY333531 returned the increased levels of amplitude of the contractions in the preterm and term myometrium to about the original levels $(0.69 \pm 0.11$ gf $)$ in the nonpregnant myometrium (Table 1). These findings suggest that PKC $\beta$ is related with the increased amplitude of smooth muscle contractions in the human myometrium during pregnancy.

In the human myometrium, it has been reported that the PKC isozyme distribution is different between the nonpregnant and the pregnant myometrium (Hurd et al. 2000), and that agonist-induced contraction is mediated by PKC isozyme activation (Eude et al. 2000). Recently, we have found that PKC activation, especially PKC $\beta$ activation, stimulated the activation processes of the smooth muscle contractile element in the human myometrium, and that the expression of РКС $\beta$ in the pregnant myometrium was significantly increased at the late stage of pregnancy (37-40 weeks of gestation) when compared with that in the nonpregnant myometrium (Ozaki et al. 2003). In the present study, we indicated that the expression of PKC $\beta$ mRNA in the term myometrium (37-39 weeks of gestation) was sixfold greater than that in the nonpregnant myometrium, in agreement with our previous report. Additionally, the expression of PKC $\beta$ mRNA was sevenfold greater in the preterm myometrium (26-36 weeks of gestation) with spontaneous contractions and fivefold greater in the preterm myometrium (27-36 weeks of gestation) with oxytocin-induced contractions than in the nonpregnant myometrium with spontaneous contractions. Thus, we

\footnotetext{
Figure 3 Effect of LY333531 on smooth muscle contractions in the nonpregnant and pregnant myometrium. (A) Effect of LY333531 (10 $\left.{ }^{-6} \mathrm{M}\right)$ on spontaneous contractions in nonpregnant $(\mathrm{Aa})$ and preterm myometrial strips $(\mathrm{Ab})$, and oxytocin-induced contractions in preterm (Ac) and term myometrial strips (Ad). (B) Control (non-treatment) smooth muscle contractions in nonpregnant, preterm, and term myometrial strips (Ba-d). The strips labeled $\mathrm{Aa}$ and $\mathrm{Ba}$ were prepared from the same nonpregnant woman. The strips labeled $\mathrm{Ab}$ and $\mathrm{Bb}$ were prepared from the same preterm woman who underwent a cesarean section for preeclampsia at 26 weeks of gestation. The strips labeled Ac and Bc were prepared from the same preterm woman who underwent a cesarean section for intrauterine growth retardation at 36 weeks of gestation. The strips labeled $\mathrm{Ad}$ and $\mathrm{Bd}$ were prepared from the same term woman who underwent a cesarean section for breech presentation at 37 weeks of gestation.
} 


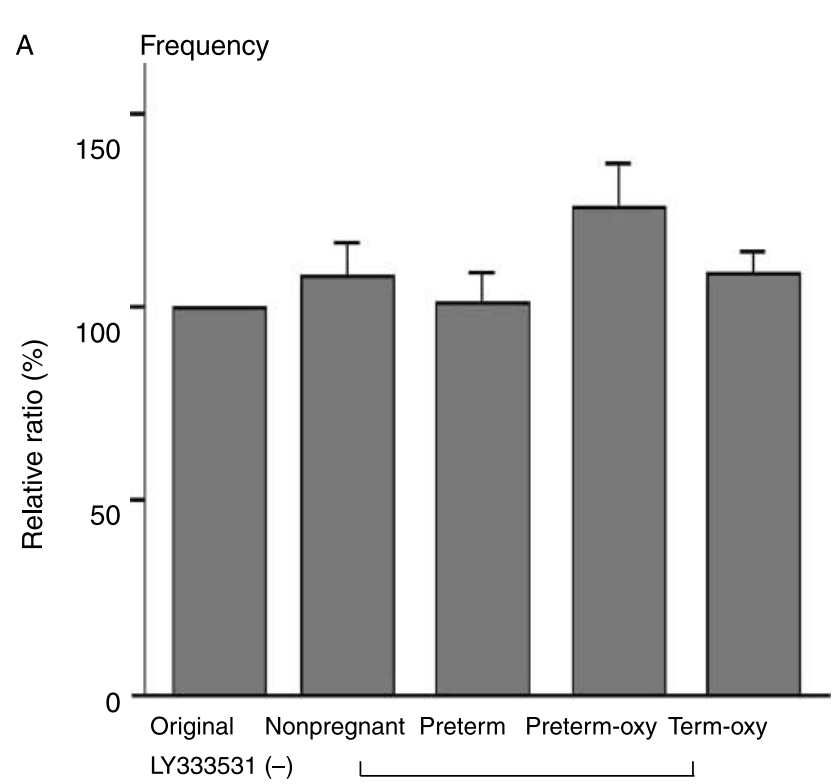

LY333531 (+)

B

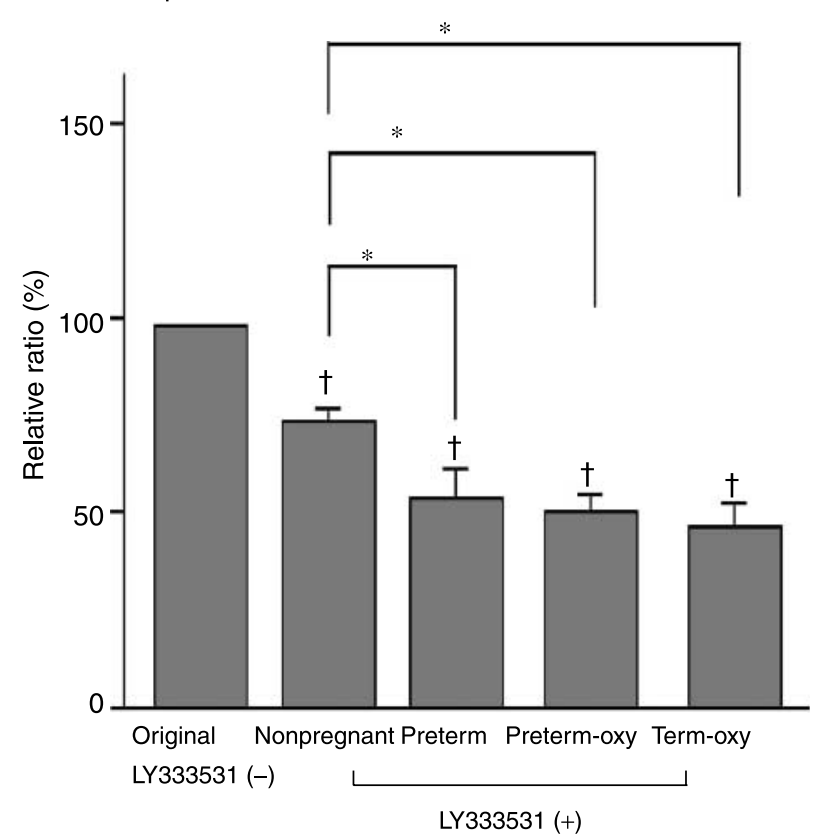

Figure 4 Comparisons in the effect of LY333531 $\left(10^{-6} M\right)$ on the smooth muscle contractions among the nonpregnant, preterm, and term myometrium. Post-treatment contractile activity in each group was presented as a relative ratio (the original value was treated as $100 \%$ ). (A) The post-treatment frequency of smooth muscle contractions in nonpregnant myometrial strips with spontaneous contractions $(n=10)$, preterm myometrial strips with spontaneous contractions $(n=5)$, preterm myometrial strips with oxytocin-induced contractions $(n=10)$, and term myometrial strips with oxytocin-induced contractions $(n=10)$. (B) The post-treatment amplitude of smooth muscle contractions in the same strips as above. ${ }^{*} P<0.01$ compared with nonpregnant myometrial strips. ${ }^{\dagger} P<0.01$ compared with the original value in each group.

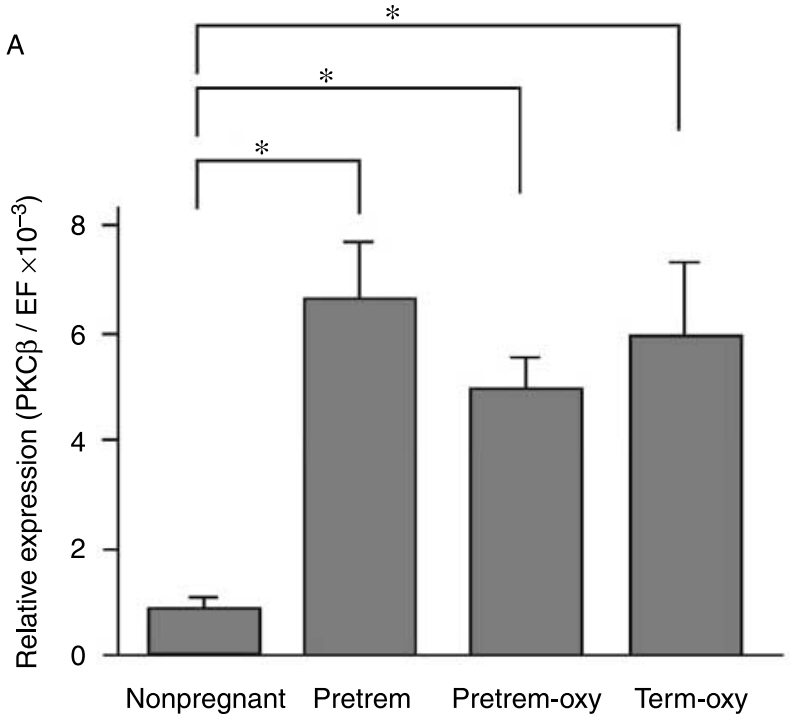

Figure 5 Expression of $\mathrm{PKC} \beta$ mRNA in the nonpregnant, preterm, and term myometrium. The expression levels of PKC $\beta$ mRNA were presented as a relative ratio to EF- $1 \alpha$ mRNA. Each myometrium was prepared from the same tissue as described in Fig. $4 .{ }^{*} P<0.01$ compared with nonpregnant myometrial strips.

have indicated that the expression of PKC $\beta$ mRNA in the pregnant myometrium is already increased significantly at the preterm stage when compared with that in the nonpregnant myometrium.

These results indicate that the increased amplitude of human myometrial contractions during pregnancy may be associated with the increased expression of PKC $\beta$, which increases the phosphorylation of MLC via the mechanism involved in inhibiting MLCP. However, PKC $\beta$ is not associated with the decreased frequency of smooth muscle contractions during pregnancy. With regard to our understanding of the change of frequency during pregnancy, further examinations will be needed to identify the mechanisms involved in regulating the frequency.

Preterm delivery remains a major obstetric problem because of the high incidence of associated perinatal mortality and morbidity. Therefore, it is crucial to prevent preterm delivery for maternal and neonatal care. The present study in the human myometrium suggests that use of an inhibitor of PKC $\beta$ may be a new strategy for the treatment of preterm delivery. However, further studies are needed to evaluate whether specific PKC $\beta$ inhibitors such as LY333531 are effective in in vivo models of preterm or term labor, and are safe for mothers and their fetuses.

In summary, the human pregnant uterus changes the characteristics of the smooth muscle contractile activity from low amplitude and high frequency to high amplitude and low frequency during pregnancy. We demonstrate that the increased amplitude of myometrial contractions during pregnancy is associated with the increased expression of $\mathrm{PKC} \beta$ in the pregnant myometrium. 
A PKC $\beta$ inhibitor may reduce abnormal uterine contractions in preterm women and prevent preterm delivery.

\section{Acknowledgements}

The authors thank for the excellent technical assistance of Ms Miyuki Imai and the secretarial assistance of Ms Wakako Okamoto and Yumi Suzuki. The authors declare that there is no conflict of interest that would prejudice the impartiality of this scientific work.

\section{Funding}

This work was supported by grants from the Japan Smoking Research Foundation and a grant-in-aid for Scientific Research from the Ministry of Education, Science, and Culture of Japan.

\section{References}

Akerlund M, Stromberg P \& Hauksson A 1987 Inhibition of uterine contractions of premature labour with an oxytocin analogue. Results from a pilot study. British Journal of Obstetrics and Gynecology 94 1040-1044.

Anwer H \& Sanborn BM 1989 Changes in intracellular free calcium in isolated myometrial cells; role of extracellular and intracellular calcium and possible involvement of guanine nucleotide-sensitive protein. Endocrinology 124 17-23.

Baraban JM, Gould RJ \& Peroutka SJ 1985 Phorbol ester effects on neurotransmission: interaction with neurotransmitters and calcium in smooth muscle. PNAS 82 604-607.

Breuiller-Fouche M, Tertrin-Clary C \& Heluy V 1998 Role of protein kinase $C$ in endothelin-1-induced contraction of human myometrium. Biology of Reproduction 59 153-159.

Chomczynski P \& Sacchi N 1987 Single-step method of RNA isolation by acid guanidinium thiocyanate-phenol-chloroform extraction. Analytical Biochemistry 162 156-159.

Eto M, Senba S \& Morita F 1997 Molecular cloning of a novel phosphorylation-dependent inhibitory protein of protein phosphatase-1 (CPI17) in smooth muscle: its specific localization in smooth muscle. FEBS Letters 410 356-360.

Eto M, Kitazawa T \& Yazawa M 2001 Histamine-induced vasoconstriction involves phosphorylation of a specific inhibitor protein for myosin phosphatase by protein kinase $\mathrm{C}$ alpha and delta isoforms. Journal of Biological Chemistry 276 29072-29078.

Eto M, Kitazawa T \& Brautigan DL 2004 Phosphoprotein inhibitor CPI17 specificity depends on allosteric regulation of protein phosphatase- 1 by regulatory subunits. PNAS $1018888-8893$.

Eude I, Paris B \& Cabrol D 2000 Selective protein kinase C isoforms are involved in endothelin-1-induced human uterine contraction at the end of pregnancy. Biology of Reproduction 63 1567-1573.

Frost P \& Nilsen F 2003 Validation of reference genes for transcription profiling in the salmon louse, Lepeophtheirus salmonis, by quantitative real-time PCR. Veterinary Parasitology 118 169-174.

Hamaguchi T, Ito $\mathbf{M}$ \& Feng J 2000 Phosphorylation of CPI-17, an inhibitor of myosin phosphatase, by protein kinase N. Biochemical and Biophysical Research Communications 274 825-830.

Hori M \& Karaki H 1998 Regulatory mechanisms of calcium sensitization of contractile elements in smooth muscle. Life Sciences 62 1629-1633.

Hurd WW, Fomin VP \& Natarajan V 2000 Expression of protein kinase $\mathrm{C}$ isozymes in non-pregnant and pregnant human myometrium. American Journal of Obstetrics and Gynecology 183 1525-1531.

Jirousek MR, Gillig JR \& Gonzalez CM 1996 (S)-13-[(dimethylamino)methyl]-10,11,14,15-tetrahydro-4,9:16,21-dimetheno- $1 \mathrm{H}, 13 \mathrm{H}$ - dibenzo[e,k]pyrrolo[3,4-h][1,4,13]oxadiazacyclohexadecene1,3(2H)-dione (LY333531) and related analogues: isozyme selective inhibitors of protein kinase C beta. Journal of Medicinal Chemistry 39 2664-2671.

Karaki H, Ozaki H \& Hori M 1997 Calcium movements, distribution, and functions in smooth muscle. Pharmacological Reviews 49 157-230.

Keirse MJ 1992 Inhibition of prostaglandin synthesis for treatment of preterm labour. In Prostaglandins and the Uterus, pp 277-293. Eds JO Drife \& AA Calder. London: Springer.

Kim BK, Ozaki H \& Lee S 1995 Increased sensitivity of rat myometrium to the contractile effect of platelet activating factor before delivery. British Journal of Pharmacology 115 1211-1214.

Kim BK, Ozaki H \& Hori M 1996 Increased inhibitory effect of phorbol ester on cytosolic Ca2 + level and contraction in rat myometrium after gestation. Japanese Journal of Pharmacology 72 111-118.

Kitazawa T, Eto M \& Woodsome TP 2000 Agonists trigger G proteinmediated activation of the CPI-17 inhibitor phosphoprotein of myosin light chain phosphatase to enhance vascular smooth muscle contractility. Journal of Biological Chemistry 275 9897-9900.

Kusaka M \& Sperelakis N 1995 Direct block of calcium channels by dioctanoylglycerol in pregnant rat myometrial cells. Molecular Pharmacology 47 842-847.

Li L, Eto M \& Lee MR 1998 Possible involvement of the novel CPI-17 protein in protein kinase $\mathrm{C}$ signal transduction of rabbit arterial smooth muscle. Journal of Physiology 508 871-881.

Loirand G, Pacaud P \& Mironneaul C 1990 GTP-binding proteins mediate noradrenaline effects on calcium and chloride currents in rat portal vein myocytes. Journal of Physiology 428 517-529.

Marc S, Leiber D \& Harbon S 1986 Carbachol and oxytocin stimulate the generation of inositol phosphates in the guinea pig myometrium. FEBS Letters 201 9-14.

Martiny-Baron G, Kazanietz MG \& Mischak H 1993 Selective inhibition of protein kinase c isozymes by the indolocarbazole Go 6976. Journal of Biological Chemistry 268 9194-9197.

Morgan JP \& Morgan KG 1984 Stimulus-specific patterns of intracellular calcium levels in smooth muscle of ferret portal vein. Journal of Physiology 351 155-167.

Morrison JJ, Dearn SR \& Smith SK 1996 Activation of protein kinase C is required for oxytocin-induced contractility in human pregnant myometrium. Human Reproduction 11 2285-2290.

Moutquin JM, Sherman D \& Cohen H 2000 Double-blind, randomized, controlled trial of atosiban and ritodrine in the treatment of preterm labour: a multicenter effectiveness and safety study. American Journal of Obstetrics and Gynecology 182 1191-1199.

Nakamoto T, Okada H \& Nakajima T 2005 Progesterone induces the fibulin-1 expression in human endometrial stromal cells. Human Reproduction 20 1447-1455.

Nishizuka Y 1995 Protein kinase C and lipid signaling for sustained cellular responses. FASEB Journal 9 484-496.

Ozaki H, Kwon SC \& Tajimi M 1990 Changes in cytosolic Ca2 + and contraction induced by various stimulants and relaxants in canine tracheal smooth muscle. Journal of Physiology 416 351-359.

Ozaki H, Zang L \& Buxton IL 1992 Negative-feedback regulation of excitation-contraction coupling in gastric smooth muscle. American Journal of Physiology 263 C1160-C1171.

Ozaki H, Yasuda K \& Kim YS 2003 Possible role of the protein kinase C/CPI-17 pathway in the augmented contraction of human myometrium after gestation. British Journal of Pharmacology $\mathbf{1 4 0}$ 1303-1312.

Phillippe M 1994 Protein kinase C, an inhibitor of oxytocin-stimulated phasic myometrium contractions. Biology of Reproduction $\mathbf{5 0}$ 855-859.

Sakata K \& Karaki H 1992 Effects of endothelin on cytosolic Ca2 + level and mechanical activity in rat uterine smooth muscle. European Journal of Pharmacology 221 9-15.

Sakata K, Ozaki H \& Kwon SC 1989 Effects of endothelin on the mechanical activity and cytosolic calcium levels of various types of smooth muscle. British Journal of Pharmacology 98 483-492. 
Sato K, Ozaki H \& Karaki H 1988 Changes in cytosolic calcium level in vascular smooth muscle strips measured simultaneously with contraction using fluorescent calcium indicator fura 2. Journal of Pharmacology and Experimental Therapeutics 246 294-300.

Sato K, Hori M, Ozaki H, Takano-Ohmuro H, Tsuchiya T, Sugi H \& Kariki H 1992 Myosin phosphorylation-independent contraction induced by phorbol ester in vascular smooth muscle. Journal of Pharmacology and Experimental Therapeutics 261 497-505.

Savineau JP \& Mironneau J 1990 An analysis of the action of phorbol 12,13-dibutyrate on mechanical activity in rat uterine smooth muscle. Journal of Pharmacology and Experimental Therapeutics 255 133-139.

Savineau JP \& Marthan R 1997 Modulation of the calcium sensitivity of the smooth muscle contractile apparatus: molecular mechanisms, pharmacological and phathphysiological implications. Fundamental and Clinical Pharmacology 11 289-299.

Schiemann WP, Doggwiler KO \& Buxton IL 1991 Action of adenosine in estrogen-primed nonpregnant guinea pig myometrium: characterization of the smooth muscle receptor and coupling to phosphoinositide metabolism. Journal of Pharmacology and Experimental Therapeutics 258 429-437.

Schrey MP, Cornford PA \& Read AM 1988 A role for phosphoinositide hydrolysis in human uterine smooth muscle during parturition. American Journal of Obstetrics and Gynecology 159 964-970.
Somlyo AP \& Somlyo AV 1994 Signal transduction and regulation in smooth muscle. Nature 372 231-236.

Somlyo AP \& Somlyo AV $2003 \mathrm{Ca}^{2+}$ sensitivity of smooth muscle and nonmuscle myosin II: modulated by G proteins, kinases, and myosin phosphatase. Physiological Reviews 83 1325-1358.

Strausberg RL, Feingold EA \& Grouse LH 2002 Mammalian Gene Collection Program Team. Generation and initial analysis of more than 15000 full-length human and mouse cDNA sequences. PNAS 99 16899-16903.

Szal SE, Repke JT \& Seely EW 1994 [Ca 2+]i signaling in pregnant human myometrium. American Journal of Physiology 267 E77-E87.

Webb BL, Hirst SJ \& Giembycz MA 2000 Protein kinase C isoenzymes: a review of their structure, regulation and role in regulating airways smooth muscle tone and mitogenesis. British Journal of Pharmacology 130 1433-1452.

Wray S 1993 Uterine contraction and physiological mechanisms of modulation. American Journal of Physiology 264 C1-C18.

Received 24 May 2006

First decision 15 June 2006

Revised manuscript received 11 December 2006

Accepted 15 January 2007 